\title{
Dirk Santvoort, Recherches curieuses de Philosophie
}

\section{Maurizio Melai}

\section{(Q) OpenEdition}

\section{Journals}

\section{Edizione digitale}

URL: http://journals.openedition.org/studifrancesi/6299

DOI: 10.4000/studifrancesi.6299

ISSN: 2421-5856

\section{Editore}

Rosenberg \& Sellier

\section{Edizione cartacea}

Data di pubblicazione: 1 novembre 2010

Paginazione: $555-556$

ISSN: 0039-2944

\section{Notizia bibliografica digitale}

Maurizio Melai, «Dirk Santvoort, Recherches curieuses de Philosophie», Studi Francesi [Online], 162 (LIV |

III) | 2010, online dal 30 novembre 2015, consultato il 08 janvier 2021. URL: http://

journals.openedition.org/studifrancesi/6299; DOI: https://doi.org/10.4000/studifrancesi.6299

\section{Questo documento è stato generato automaticamente il 8 janvier 2021.}

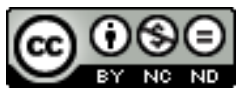

Studi Francesi è distribuita con Licenza Creative Commons Attribuzione - Non commerciale - Non opere derivate 4.0 Internazionale. 


\title{
Dirk Santvoort, Recherches curieuses de Philosophie
}

\author{
Maurizio Melai
}

\section{NOTIZIA}

DIRK SANTVOORT, Recherches curieuses de Philosophie (1714), Édition critique établie par Emilio SERGIO, Paris, Champion, 2009 («Libre pensée et Littérature clandestine» 38), pp. 401.

1 Grazie alla presente edizione di Emilio Sergio, le Recherches curieuses de Philosophie, opera citata per la prima volta nel 1912 da Gustave Lanson e da allora catalogata come anonima, sono finalmente associate al nome di un autore. Come dimostra l'editore, fu Dirk Santvoort, naturalista dilettante vissuto nei Paesi Bassi tra il 1652 ed il 1712, a comporre quest'opera filosofica eterodossa assai curiosa ed originale. 0 meglio, Santvoort pubblicò nel 1699 un testo in lingua olandese che, tradotto in latino nel 1713 con il titolo di Curiositates philosophicae sive de principiis rerum naturalium dissertatio selecta, cominciò a circolare anonimamente anche al di fuori dei confini olandesi e ad interessare i più illustri esponenti europei del libero pensiero filosofico. L'edizione latina del $1713 \mathrm{fu}$ il testo di riferimento per la traduzione francese del 1714, traduzione che Emilio Sergio attribuisce, con argomenti pienamente convincenti, a Boulainvilliers. L'ampia diffusione (clandestina) che il manoscritto del 1714 conobbe, grazie soprattutto al prestigio del suo traduttore ed a quello della lingua francese, conferisce alla presente pubblicazione delle Recherches curieuses - prima edizione critica del manoscritto 9107 del "Fonds français" della Bibliothèque Nationale de France - un ulteriore interesse storico e filosofico.

Quanto ai contenuti dell'opera, Santvoort concepisce le sue Recherches come un trattato di fisica e di cosmologia. Punto di partenza della riflessione filosofica è la constatazione empirica di un fenomeno naturale, eretta dall'autore ad assioma fondamentale: il fuoco non può prodursi ed alimentarsi che grazie all'aria; isolato dall'aria, esso perde infatti 
la propria identità e si tramuta in un elemento diverso, solido e freddo. A partire da questo assioma, Santvoort cerca di superare il meccanicismo cartesiano elaborando una fisica vitalistica ibrida ed eclettica, che risulta dall'unione sincretica tra elementi della tradizione medica e tratti del pensiero platonico, stoico ed epicureo. Il sistema che egli costruisce si fonda principalmente sull'individuazione di una serie di leggi termiche che regolano lo sviluppo della materia e sulla reinterpretazione del concetto tradizionale di semina rerum. L'universo, che ha un'estensione infinita e che comprende un numero infinito di mondi, era composto in principio da una materia flui-da, calda e salata, detta "materia primordiale"; dalla concrezione o dalla coagulazione di parti infinitamente piccole di tale materia primordiale - messe in movimento da una serie di scambi termici che determinano, secondo leggi precise, l'attrazione o la repulsione tra particelle di materia - si formano i "semi primordiali", da cui traggono origine a loro volta tutti i corpi solidi, gli esseri e le specie viventi presenti in natura. Fu questo atto iniziale ad innescare il ciclo, destinato a durare in eterno, della formazione e della corruzione dei corpi solidi: da tempo immemorabile, i mondi nascono e muoiono ciclicamente a causa della trasformazione continua della materia primordiale. Convinto dell'idea che l'intero universo sia in continua trasformazione, che nulla si crei e nulla si distrugga, Santvoort rifiuta il concetto di creatio ex nihilo, escludendo dalla propria cosmologia l'atto creatore divino. Dando prova di audacia e radicalismo filosofico, Santvoort spiega il passaggio dal caos originario all'ordine cosmico attraverso il concetto di seme e le leggi dello scambio termico, che rendono del tutto superfluo l'intervento primordiale e ordinatore di Dio. In tal modo, individuando una forza vitale insita nella materia, capace di determinare l'attrazione o la repulsione tra parti della materia stessa, l'autore delle Recherches sostituisce al meccanicismo cartesiano una sorta di "vitalismo materialistico".

3 Espressione di una nuova concezione materialistica della natura, l'opera di Santvoort riflette la contestazione e la crisi che colpisce il cartesianismo tra la fine del Seicento e l'inizio del Settecento. All'interno del fermento anticartesiano, essa dà voce in particolare alle posizioni eterodosse di coloro che, nel periodo di transizione dall'epoca classica all'età dei Lumi, professano clandestinamente un ateismo ed un materialismo radicali. Sono proprio la radicalità e l'originalità di pensiero ed al tempo stesso la capacità di riflettere significativamente un'epoca di cambiamento che fanno delle Recherches curieuses di Santvoort - rese accessibili dalla preziosa edizione di Emilio Sergio - un testo interessante da riscoprire e rivalutare. 